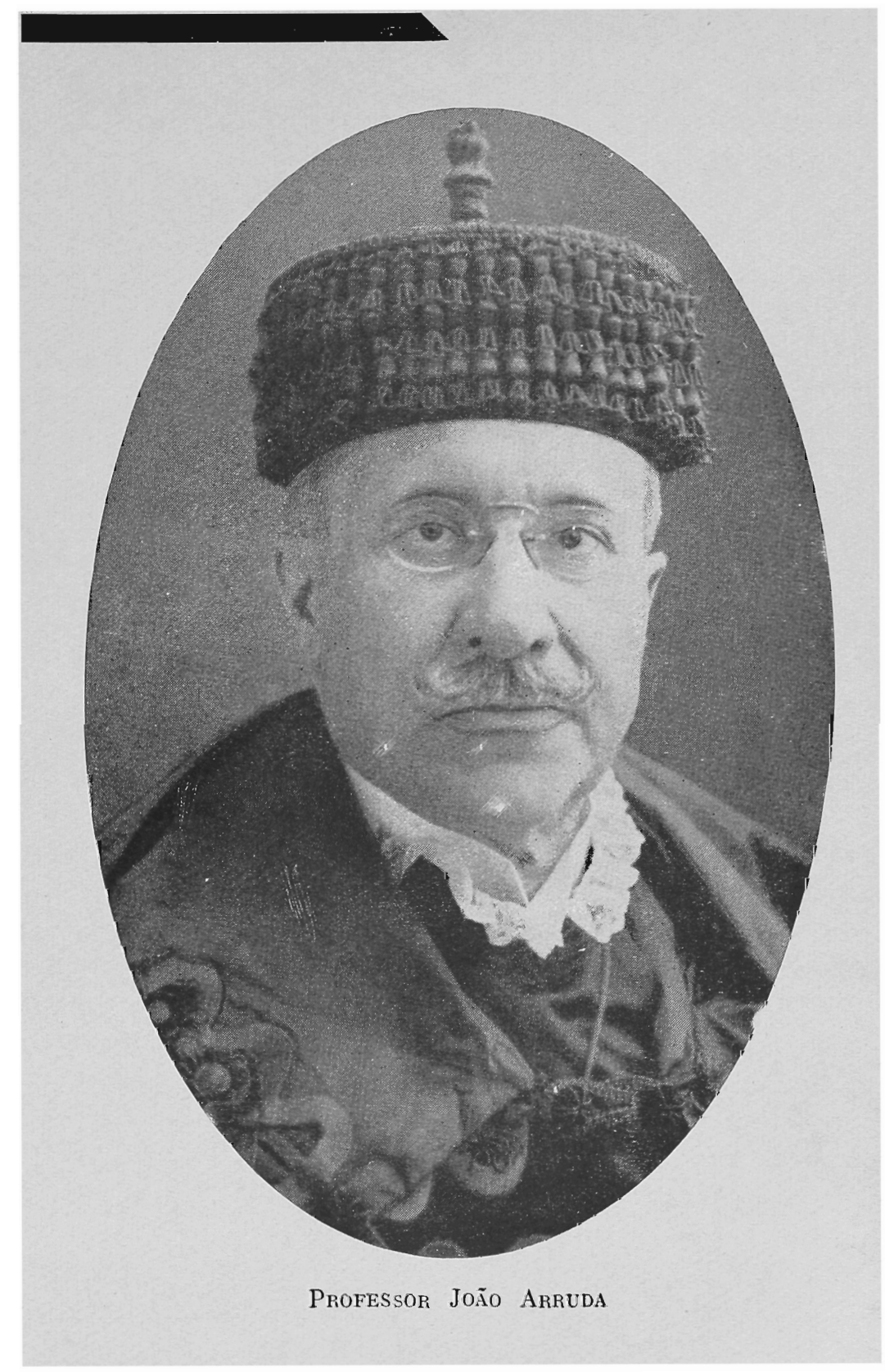




\section{Professor João Arruda (*)}

\section{Spencer Vampré}

Quando cerrou os olhos à luz deste mundo, para abri-los na eternidảde, depois de longa e fecunda existencia, que se dilatou por oitenta e dois anos, levou o Prof. JoÃo Braz de Oliverra Arruda a certeza de que vivera nobremente, e de que deixara nesta tradicional Faculdade de Direito profundamente gravada a sua lembrança.

Poder-se-á mesmo dizer que sempre, em todo o extenso peregrinar, constituio esta Faculdade o principal objeto do sec carinho, e o contacto com a mocidade estudiosa o maior deleite do seu espirito. Com os olhos nela, batalhou e estudou, e manejando a pena como professor, como publicista e como advogado, amou intensamente a justiça e aspirou incansavelmente esculpir dentro de si mesmo a imagem perfeita do cultor do direito.

$\mathrm{E}$ ninguem melhor do que ele sentio o tormento do que estuda e perscruta; indaga e conjetura; analisa e debate; mas, ao mesmo tempo, frequenta o pretorio; ouve o cliente; imagina e realisa a estrategia dos debates; e procura tirar dos ensinamentos da doutrina a solução imediata das questões vigentes.

(*) Discurso pronunciado, a 24 de novembro de 1944 , na sala "João Mendes Junior", em nome da Congregação da Faculdade de Direito, quando da comemoração do falecimento do saudoso professor emérito. 


\section{o ADVOGADO}

Ha alguma cousa do general no advogado, que não esterilisa o espirito doutrinario ao contacto com o Fôro. Tudo deve prever, e para tudo contar com remedios prontos e eficazes; ha de imaginar a ação a propôr, ou a defesa a iniciar; ha de reunir e de pesar as provas, que ulteriormente apresentará; ha de figurar as reações emocionaes do juiz e do advogado contrario; ha de compreender, de relance, e por uma especie de faro instintivo, o que poderá concorrer para a vitoria ou para a derrota. E em tudo, e por tudo, ha de empenhar-se com o denodo de quem luta por uma causa justa. Mas, de outra parte, ha de refletir, com sobriedade e com sangue frio, mesmo deante do perigo iminente; ha de usar a fórma cortez e serena, mesmo deante do sarcasmo e do odio; ha de sobrepairar às paixões dos contrarios, e às do seu proprio cliente e amigo; ha de ser justo bastante para distinguir, no emaranhamento dos combates, aonde está o caminho do triunfo, e marchar para ele corajosamente, não obstante os tropeços, que juncam o solo.

Deve o advogado, como o general, ser suficientemente culto para conhecer as lições das batalhas alheias; ter a coragem das iniciativas, que surpreendem e abatem o adversário; desfechar golpes inopinados e incisivos. Deve confiar e esperar da compreensão dos juizes; mas, deve velar e lutar indefessamente até o final triunfo, examinando e reexaminando, a cada momento da luta, os prognosticos do seu desfecho.

Foi o prof. João Arruda um bravo e culto advogado, um dos mais corajosos e ilustres que o Fôro de São Paulo, com tão nobres tradições, conheceu em qualquer tempo. Com ele, por adversário, tivemos ensejo bastas vezes de terçar armas, em pleitos renhidos em que delicadissimas questões de honra e pundonor, ou avultados haveres e cubiças, se focalizaram na tela judiciaria, ao mesmo tempo que as paixões e as intransigencias de nossos clientes tornavam as 
pelejas sobremodo implacaveis. Pois bem: queremos dar aqui publico testemunho de que jamais, no maior torvelinho dos recontros, deixou o Prof. João Arruda de manter aquela linha de superior elegancia e de estrita cortezia, que distingue o verdadeiro advogado do simples postulante forense.

Como causidico militante, inestimaveis serviços e preciosas iniciativas lhe devem o Instituto dos Advogados, de que foi fundador, e a Ordem dos Advogados, onde, por sua iniciativa, se amparam, ainda hoje, colegas desafortunados ou vencidos. As páginas que deixou escritas, nos seus "Quarenta anos de Vida Forense", retratam bem a nobreza do seu carater e a sinceridade de suas lições. Pode bem ser que, aqui ou ali, no constante lidar de paladino de direito, um gesto de impaciencia deante das provocações de adversario, ou de revolta ante a injustiça de um julgamento, o tenha feito revidar com acrimonia, ou criticar com a pena molhada em fel. Mas, essa impaciencia, ou essa revolta, se explicam em quem ama a justiça e combate pelo direito, e por isso mesmo sofre e desespera ao pressentir, na injustiça e na violencia, o remate de tantos esforços.

\section{o PROFESSOR E O PUBLICISTA}

Professor de direito, ele o foi com uma constancia, un zelo e uma tenacidade, raro igualados, e nunca excedidos. Homem de partido, diremos melhor, pensador e idealista politico, lançou-se nas primeiras hostes do Partido Democratico com ardor juvenil, que estimulava os moços, e retemperava as fibras aos mais velhos, escrevendo, falando, propondo, votando, sugerindo, com uma fé construtiva, com uma coragem intelectual, com uma liberdade de critica, de que os anaes partidarios, as colunas dos periodicos, e as assembléas politicas guardam preciosa documentação. Foi, sem favor, um dos mais puros idealistas que S. Paulo tem gerado, em seu seio fecundo em pensadores e em estadistas. 
Mais ainda: - procurou sempre harmonisar a etica e a politica, desconfiado do preceito maquiavelico de que os fins justificam os meios. Dentre as desilusões, que o desenrolar dos acontecimentos politicos em nossa Patria fez nascer em seu animo, nunca pregou a violencia, a ilegalidade, o sofisma. Muito ao contrario disso: não esqueceu as quatro virtudes naturaes dos gregos, que São Tomaz perfilhou - a prudencia, a justiça, a coragem, a moderação.

Já se afirmou que toda vida é um sonho da mocidade realisado na idade madura. Pode dizer-se que toda a vida do Prof. João Arruda se resume neste conceito: amou as letras e a justiça. Si lhe seguirmos, passo a passo, o curriculo vital, encontraremos sempre esses dois amores como bussola de sua vida.

\section{TRAÇOS DE FAMILIA}

Nasceu o prof. João Arruda, na Fazenda Cascata, no Bananal, na então Provincia de S. Paulo, filho legitimo de Manoel Braz de Sousa Arruda e Dona Alda Maria Cardoville Barboza de Souza Arruda. Constituia então o Bananal um dos centros agricolas mais importantes, sinão o mais importante, do Brasil, e ali se reuniram brasileiros de nobre estirpe, cujos antepassados tinham derramado o sangue em lutas contra os mouros e contra os hespanhoes, em defensão da Corôa Portugueza. Os Oliveiras, os Barbosas, os Ramos, os Almeidas, os Souzas, os Nogueiras, os Arrudas, constituiram verdadeira aristocracia de grandes proprietários ruraes, que viviam à lei da nobreza, dispunham de avultados haveres, de numerosa escravaria, e educavam os filhos na Europa, donde vinham as louças, e as pratas, os objetos de uso domestico mais fino, e os enxovaes para as bodas e festas mais requintadas.

Guardam vetustos casarões do Bananal, e das cidades circumvizinhas, outrora ricas vivendas senhoriaes, - a lembrança desses tempos idos, de galanteria e de fausto, em que 
damas prendadas e donzelas romanticas se alternaram ou se entrecruzaram, nas genealogias, com comendadores e moços fidalgos, veadores e cavalheiros da Imperial Casa e das Ordens de Cristo e da Rosa, em intrincados parentescos que sucessivos casamentos entre conjuntos tornaram sobremodo complicados.

Na graciosa residencia do nosso eminente colega Prof. Braz de Souza Arruda, tivemos ensejo de percorrer os documentos genealogicos de sua ilustre progenie, e de compartilhar do enlevo com que ali as tradições da familia se enlaçam às velhas lembranças, enquanto as trepadeiras do jardim enfloram de graça e de doçura os livros severos, alinhados nas preciosas estantes.

Aqui está uma tela, pintada em Paris, em que o avô sorri quasi imperceptivelmente na luz dos olhos claros, como que a esbater a gravidade da pose pictorica. Ali um tio avô, gordo e anafado, em cujo corpanzil se retrata o bem comer, mas em cujo olhar, inteligente e penetrante, se adivinha a leveza do espirito em contraste com o peso do corpo. Possuissemos nós a graça evocadora da imaginação, e fariamos descer dos paineis essas figuras venerandas, que nos recontariam jornadas asperas de Portugal, ou tranquilos cenarios de França; incidentes curiosos do Primeiro ou do Segundo Imperios; casos jocosos da vida quotidiana, de envolta com demandas e lutas partidarias; horas tenebrosas, em que os odios incendiaram as almas e noites serenas e tranquilas em que o luar inundava as fazendas, em que os escravos cantavam docemente à roda das fogueiras, e as creanças chilreavam pelos terraços perfumados de madre-silvas.

Foi num ambiente assim, que ainda espera uma suave alma evocadora, que, com as tintas da saudade e da arte, resuscite este mundo extinto, - foi num ambiente assim, que nasceu, em 16 de Abril de 1861, o nosso Prof. Joño ArRUDA, a quem nos ligariam depois tantos vinculos de admiração e de afeto. E quando rememoramos que nesse mesmo Bananal, na Fazenda Loanda, viera à luz, alguns antes dele, o nosso querido, o nosso eminente Prof. José LuIz DE 
Almeida Nogueira, do mesmo tronco genealogico do Prof. .Joño ArRuda, as figuras dos dois grandes Mestres se irmanam em nosso culto e revivem em nossa recordação.

Enquanto se guardar a lembrança dos tempos idos e vividos, enquanto palpitar na alma de nossa gente o fogo vestal da gratidão aos nossos maiores, as figuras de Josḱ Luiz de Almeida Nogueira, o pae da Historia desta Academia, e a do Prof. Joño Arruda, o devotado e indefesso cultor da filosofia do direito, hão de viver e fulgir na memoria dos moços.

Mas, retornemos aos traços biograficos. Em Barra Mansa, no Colegio do dr. Miguel Arcanjo, que ainda vive na memoria dos velhos moradores, salmodiou o futuro professor as primeiras letras. Pouco depois, eil-o na Côrte, no Colegio Abilio, dirigido pelo inclito educador dr. AbILIo Cesar Borges, depois Barão de Macaúbas, - a quem a mocidade brasileira deveu serviços inegualaveis. $\mathrm{Si}$ as atribulações da vida quotidiana nos derem algum dia um pequeno resfolego, tentaremos escrever umas memorias sobre os professores do ensino secundario, pelo menos de S. Paulo, mais ligados à historia desta Faculdade, afim de conservar os materiaes com que os futuros historiadores delineiem, a grandes traços, a formação mental e moral dos nossos moços. Nessa memoria os Mortons, os Moretzohns, os Vicente Mamedes, os Luiz Antonios, os lentes do Culto à Ciência de Campinas, os do Colegio S. Luiz de Itú, do nosso Curso: Anexo, e tantos e tantos devotados mestres dos moços, cujas lembranças se vão lentamente delindo, hão de nascer das cinzas do passado e viver outra vez na verdadeira imortalidade, que é a imortalidade do espirito.

Aos 17 de abril de 1877, contando apenas dezeseis anos de idade, eis o nosso futuro Mestre, matriculado no primeiro ano, entre os pávidos calouros, sempre amedrontados ante a perspectiva do trote academico, o medo de perder o ana por faltas, e as primeiras dificuldades do Curso Juridico, que parecem inextricaveis. Eis aqui um estado mental coletivo, que deve ser tomado em conta pelos professores do 
primeiro ano juridico: - lutam os pobres calouros com dificuldades que lhes parecem invenciveis, de apreender os problemas juridicos; de habituar-se às abstrações das escolas, de afeiçoar o acumen dialetico de que tanto se usa e se abusa no curriculo academico; de compreender, de relance, a complicada teia de termos tecnicos e de conceitos historico-filosoficos, que, subitamente, e em catadupa, sobre eles jorram os lentes.

Eis aqui um fato pedagogico, que impressionou sempre o nosso Mestre João Arruda, e que o tornou mais tarde explicador paciente e persuasivo, ao mesmo tempo que julgador compreensivo e benevolente.

\section{OS CONDISCIPULOS}

Eil-o agora, o nosso futuro professor, assentado entre os condiscipulos, no velho e tradicional edificio da Academia, a que a reforma de Dino Bueno, não alterara ainda as feições primitivas, e a reconstrução de Alcantara Machado ainda não mudara a primitiva arquitectura. Aqui, estão, a seu lado, nos toscos bancos de pau, entre as paredes caiadas e tão espessas, que dentro de suas taipas ha tumulos de frades, - aqui estão moços cujas frontes serão um dia engrinaldadas de louros; Francisco de Paula Paiva Baracho, depois juiz ilustre em São Paulo; Job Marcondes de Rezende, tipo perfeito de advogado pela ilustração e pela honradez; Estevão Leão Bourroul, que justamente se cognominou o Veuillot Brasileiro, lider católico e investigador paciente da historia patria; Jullo dE Castilhos, chefe inolvidavel dos republicanos do Rio Grande do Sul, e cuja imagem ficou gravada em nossos corações como a de um dos fundadores da Republica; Joño Passos, de cujos talentos confiou São Paulo, por largos anos, a Procuradoria Geral do Estado; Manoel Ignacio Carvalho de Mendonça, um dos deuses lares do direito nacional, a quem se devem a Doutrina Pratica das Obrigações, os Rios e Aguas Correntes e os Contratos no 
Direito Civil Brasileiro; Eduardo Prado, o autor da Ilusão Americana e dos Fastos da Ditadura Militar, a quem EÇA DE QueIroz tomou por modelo, na figura de Jacyntho, da $A$ Cidade re as Serras, o mais sugestivo e delicado dos seus romances.

Parece já suficientemente longa e brilhante esta lista. Ha, porém, mais ainda. Entre os estudantes, veremos Theophilo Dias, o poeta da A Comedia dos Deuzes, e Valentim Magalhães, poeta, critico, jornalista, que ocupou na Academia Brasileira de I etras a cadeira de Castro Alves e que arrancou aplausos a Portugal e ao Brasil. Veremos ainda dois grandes professores futuros desta Casa - RAFaEL Corrêa da Silva Sobrinho, e o nosso João Arruda, tão diversos pelo temperamento, pelas inclinações da mente, como notaveis pelas peregrinas qualidades de professores e de jurisconsultos.

Vinha a nova turma de estudantes encontrar na Academia moços na altura dos seus talentos e que com ela disputariam as glorias e os aplausos. Aqui estão no segundo ano: LeOPoldo DE BulHões, o eminente economista e ministro da Fazenda da Presidencia Rodrigues Alves; José JoAquim CARdoso de Melo Junior, notavel advogado, felizmente ainda vivo, pae do nosso querido e eminente colega Prof. Cardoso de Melo Neto; Ezequiel Freire, o mimoso poeta das Flores do Campo, patrono da cadeira que na Academia Paulista de Letras ocupa tão fulgidamente o nosso Mestre Prof. SoAres de Melo; João Batista dA Silveira, poeta, jornalista, advogado, e patriarca de uma familia privilegiada de talentos - Alarico Silveira, Breno Silveira, Valdomiro Silveira, Dinorah Silveira de Queiroz, Miroel Silveira; Afonso Celso Junior, o futuro Conde de Afonso Celso, autor do Porque me Ufano do Meu Paiz; Filadelfo de Castro, Campos Pereira, ilustres Ministros do nosso Tribunal de Justiça; Carlos Augusto de Freitas Vilalva, a quem os anais judiciários devem serviços de extraordinaria significação; e Antonio Lutz dos Santos Werneck, depois ilustre Juiz em S. Paulo, - o melhor estudante desta turma. 
Estão no terceiro ano: José Anțonio Pedreira de Magalhẫes Castro, Antonio Caio da Silva Prado, Adolfo Gordo, Severino Prestes, que depois foi professor desta Casa.

No quarto ano: José Gomes Pinheiro Machado, o futuro General Pisheiro Macdado; Julio Benedicto Ottoni, Pedno Mariani Junior; João Pereira da Silva Cotinentino, Jỗo Baptista Sampaio Ferraz.

No quinto ano: Lucio de Mendonģa, Manoel Corrêa Dias, Estevam Rubeiro de Rezende, e dois futuros lentes de grande nomeada Brazilio dos Santos e JoÃo Mendes Junior.

Aqui está, a grei estudantil em alguns dos nomes que nos acudiram mais facilmente. Vejamos os Mestres, que acompanham a Congregação em 1877: - Em direito natural, no primeiro. ano, Jỗo Teodoro. Em direito constitucional, Leoncio de Carvalio e tambem Sá e Benevides. Em direito eclesiastico, o Conego Andrade. Em direito civil, Falcão Filho e Justino de Andrade e, como substituto, Vieira de Carvalho. Em direito criminal, José Bonifacio, e tambem como substitutos, João Teodoro e Leoncio de Carvalho. Em direito comercial Antonio Carlos. Em processo civil e criminal, Ramalho. Carrão, em economia politica; e, como substituto, Joaquim Augusto de Camargo. Em direito administrativo, Furtado.

Era pequena a Congregação; pequeno o edificio da Escola; pequenas as turmas de cada ano, como pequena a cidade de então. Mas, eram grandes as almas e as aspirações, os impulsos e a avidez do saber, e sobretudo grande a influência intelectual e moral da Academia de Direito, que constituia então, como ainda hoje, o mais legitimo orgulho de S. Paulo, que sabe que ela tem sido sempre, é agora, e será no futuro, incansavel obreira da Patria.

Sinão vejamos: - a turma do Prof. João Arruda vê entrarem, no ano seguinte, de 1878: - Augusto de Lima e Raymundo CorrêA, dois grandes poetas; Alfredo Bernardes e Filinto Bastos, dois grandes jurisconsultos e professores de direito; Capote Valente, Zeferino de Faria, Daniel Machado, Manoel Tamandaré, advogados de renome; Oscar 
Pederneiras, o humorista da "Corte em Ceroulas"; Cyro DE Azevedo, Assis Brazil, e Silva Jardim, tres apostolos da ideia republicana; Julio dE Mesquita, o preclaro jornalista, e Firminnó Pinto, a quem S. Paulo deve serviços inestimaveis. Em 1879, alistam-se entre os calouros - TEODoro DE Carvalho, Martim Francisco Sobrinho, José Getulio Monteiro, Plinio Uchôa, Teodoro Reichert, Adolfo Maia, Pennaforte Mendes de Almeida, Luiz Piza, Antonio de Padua Sales, David Campista, João Alberto Salles, e outros e outros, entre os quaes não esqueceremos Pedro Lessa, que iria mais tarde aplaudir o prof. Joño ArrudA, no concurso que the deu acesso ao professorado.

Ainda em 1879, sobrevém a lei do ensino livre, conhecida por Decreto Leoncio de Carvalho, que tão fundas e largas repercussões registrou em nossa historia academica.

Em 1880, aos 16 de fevereiro, chameja nesta Faculdade o incendio, que tão profundamente sacrificou o nosso arquivo. E nova turma vem abancar-se no primeiro ano: Edmundo Muniz Barreto, Godofredo Cunha, Sebastião de Lacerda, Carlos de Oliveira Figueiredo, futuros Ministros do Supremo Tribunal Federal: Julio MaIA, o nosso sempre lembrado e querido secretario; Antonio Lobo, Olavo Egidio, Gastão da Cunha, Sabino Barroso, José Pereira de Queiroz, Eugenio Egas, Pedro Tavares, José de Campos Novaes.

Em 1881, finalmente, achando-se o Prof. Joño Arruda no quinto ano, eis que as hostes academicas se renovam com brilhantes talentos: - Jesuino Cardoso, José Mandel de Azevedo Marques, Estevam de Almeida, tres lentes ilustres; EnÉas Galvão, brilhante figura de magistrado, como seus colegas, Juvenal Malheiros e Primitivo Sette de Castro; Raul Pompeia o autor do "Atheneu"; Luiz Murat, o poeta das "Ondas"; Joấo Batista de Oliveira Penteado e Cincinato Braga, advogados eminentes, felizmente ainda vivos; Fortunato Moreira, Rodrigo Romeiro, e tantos e tantos, entre os quaes não esqueceremos o dr. Antonio Candido de Camargo, que logo abandonou o direito pela cirurgia, de que é uma gloria. 


\section{VIDA LITERARIA E JORNALISTICA DA ACADEMIA.}

Haveis de excusar tão larga nominata. E' que desejámos sugerir-vos à imaginação o brilho intelectual dessa mocidade, contemporanea do Prof. JoÃo Arruda, entre cujos fulgidos talentos se lhe formou a vigorosa inteligência, ede muitos dos quaes recebeu, pela vida em fóra, testemunhos do mais alto apreço. Si a emulação é um estimulo psicologico, e si a comparação das nossas possibilidades com os alheios meritos, nos fortifica na conquista do exito, ninguém poderá negar a influencia profunda, que o meio intelectual em que plasmamos a personalidade, exerce sobre o nosso desenvolvimento futuro. Tal se deu com o Prof. Joño ARRUDA, em meio à mocidade irrequieta e ardente do seu tempo, dividida entre republicanos, catolicos, liberaes e conservadores. Surgem em 1877 a Reação, orgão do "Circulo de Estudantes Catolicos"; O Labarum, dirigido por EduardoPrado e Valentrm Magalhães, com a sua coluna de "Cronica Politica"; O Liberal, voz do Clube Liberal Academico: A Opinião Republicana, redigida por Afonso Celso Junior, Lucio de Mendonça, Fontoura Xavier, Pamphilo de Alburquerque e Generino dos Santos. Funda-se o Ateneu Juridico Literario e Beneficente, sendo presidente Antonio MAnhäes Campos e vice-presidente Manuel Antonio Dutra RODRIGUES.

Em 1878, entra $A$ Republica no seu terceiro ano de publicidade, sendo redator chefe Manhães de Campos, e redatores parciaes Pedro Sampaio Ferraz, Caio Prado, Afonso Celso Junior, Teofilo Dias, Gonzaga Jayme, Pelino Guedes, Alonzo Guayanaz da Fonseca e Urbano do Amaral. Ainda. em 1878, se funda a sociedade Fraternidade Literaria, a qual edita uma Revista, redigida por JoÃo JacINTHO DE MENDonÇA Filho, Afrodisio Vidigal e Leopoldo Telxeira Leite. 0 Ateneu Juridico e Literario tambem publica a revista mensal Direito e Letras, sendo redator juridico Tristão Pereira da Fonseca, e redator literario Afonso Celso Junior, com a 
colaboração de Assis Brasil, Pelino Guedes, Silva Jardim, Valentim Magalhães, Teofilo Dias, Santos Werneck, Souza Fernandes, Cardoso de Melo, Fernando Mendes e Severino Prestes.

Em 1879, continuava $A$ Reação, como orgão do Circulo de Estudantes Catolicos, sob a chefia de Rafael Correia da Silva, e com a colaboração de Filinto Bastos, Valois de Castro, José Vicente de Azevedo e outros. A seu lado surgem $A$ Vanguar ${ }^{k} a$, redigida por Estevam Leão Bourroul e o Monitor Catolico, sob a direção de Estevam Bourroul e TIburtino Mondim Pestana, este não pertencente ao corpo academico, mas espirito culto e devotado às letras, cuja memoria gentil S. Paulo guarda com carinho e guardará sempre.

Em 1880, no primeiro semestre, assume a direção d'A Riepublica, Afonso Celso Junior, e, no segundo semestre, Julio de Castillos, ao mesmo tempo que colaboram como redatores parciaes Manoel Ignacio Carvalho de Mendonça, Aristides Maia, Angelo Pinheiro Machado, Antonio Mercado, Pedro lessa, Augusto de lima, Oscar Pederneiras, Cyro de Azevedo e outros. Em campo adverso, continua A Reação, sob a direção de José Valois de Castro, José Vicente dE Azevedo e Queiroz Carreira. Surgem novos periodicos: O Fiederalista, de propaganda republicana, sob a direção de Pedro lessa, Alberto Salles e Alcides lima; A Evolução, no mesmo sentido, sob a direção de Julio de Castillos, Assis Brasil e Pereira da Costa, e a Revista de Ciencias $e$ Letras sob a direção de Raymundo Corrêa, Alexandre Coelho, Randolfo Fabrino e Augusto de lima.

Em 1881, finalmente, quando o nosso Mestre Prof. João ArRuda está no quinto ano, sobrevém nova florada jornalistica: - A Comedia, redigida por Valentim Magalhães, Adolfo Maia, Gustavo Pacca e Silva Jardim; o Éntreato, que substituio logo a Comedia, sob a direção de Valentim MAgalhães e Ezequiel Freire; O Americano, sob a chefia de Cyro de Azevedo e Sá Viana, e, por ultimo, o Nove de Setembro, orgão do Clube do mesmo nome, redigido por Bulhóes Pedreira, Raul Pompeia, Lacerda Werneck e Xa- 
vier da Silveira, e cujo titulo lembra o conflito academico de 9 de Setembro de 1878, originado de excessivos trotes contra os calouros.

\section{O IDEALISMO REPUBLICANO}

E' com pezar que omitimos aqui muitos sucessos que a cronica recorda, e cuja narrativa aumentaria o movimento mental dessa agitada época. Foi moda, por muito tempo, detrair-se a republica, com repetir a frase atribuida a ArIsTIDEs LoBo, de que o povo assistira bestifiçado à sua proclamação. Quem apenas relanceie os olhos por estes nomes e por estes jornaes academicos, ha de sentir que, si em algum logar palpitou a chama republicana inextinguivelmente, foi sob as arcadas do velho convento, onde nunca deixaram, nem nunca deixarão, de escoar os anceios da patria. Por isso mesmo, é a mocidade academica, hoje, como ontem, profundamente impaciente ante os problemas da Patria, e os excessos que pratica, e os juizos que antecipa, de antemão os absolvem o ardor das convicções e a sinceridade das atitudes. Algumas vezes, no contemplar os dramas presentes do Brasil e do mundo, nos pomos a considerar que é esta Faculdade ainda, e sempre, manancial vivo de democracia e de cultura, verdadeira oficina do Brasil, onde se forjam os corações e os talentos para as conquistas da gloria. E mais ainda: si ela desaparecesse, por desgraça nossa, uma noite caliginosa e tetrica envolveria a alma brasileira, que se sentiria perdida e sem norte como os heroes troianos no poema que Homero imortalisou.

Em tantas e tão acesas lutas, não consta que tomasse parte saliente o nosso Mestre Prof. JoÃo Arruda, - ou porque não acreditasse muito na eficacia das discussões ideologicas, ou porque, reservado e timido, quizesse silenciosamente brunir as armas com que mais tarde sairia destemidamente a campo. 
Em 5 de novembro de 1881, eil-o que se diploma, e se despede desta Faculdade.

\section{DE NOVO O ADVOGADO}

Torna-se a principio advogado. Logo depois abraça a magistratura; e a 11 de junho de 1886 toma posse como Juiz substituto de Jaboticabal.

No ano seguinte remove-se para Campinas, ainda como juiz substituto, e ali completa o quatrienio, a 11 de junho de 1890, voltando de novo à advocacia. Faz-se por muito tempo, fazendeiro no patrio Bananal, na mesma fazenda em que nascera, a da Cascata, e ainda na Fazenda do Alto, em Barra Mansa.

Em 1889, vagando-se a cadeira de direito romano pela morte de Dutra Rodrigues, sae nomeado para ela Americo Brasiliense, abrindo-se vaga de substituto. Ao concurso, se candidataram o dr. JoÃo José de Araujo, o dr. JoÃo Mendes de Almeida Junior e os bachareis José Gervasio Benevides de Queiroz Carreira, Fernando Pacheco de Vasconcelos e Joño Braz de Oliveira Arruda. Por faltarem quaesquer documentos para a inscrição, não foram os dois ultimos considerados inscritos.

Procedendo-se ao concurso, lograram classificação, em primeiro logar, JoÃo Mendes Junior; em segundo, JoÃo José de Araujo; e em terceiro, José Gervasio. Foi João Mendes nomeado a 31 de agosto, tomando posse a 10 de setembro de 1889, nas vesperas da proclamação da republica.

\section{DE NOVO O PROFESSOR}

Durante esse tempo, estuda o prof. Joño Arruda indefessamente, segundo o seu habito, deita-se cedo; levanta-se antes do sol, e lê e medita, anotando os livros e os cadernos com paciente e incessante labor. Em 1896, transfere a re- 
sidencia para Ribeirão Preto, onde dentro em pouco se torna fazendeiro e conquista universal apreço pela lhaneza, pela erudição e pelas excelsas qualidades moraes. Ainda residia nessa cidade quando veio opor-se ao concurso, em 1906, aberto pela promoção de Rexnaldo Porchat a catedratico de direito romano.

Esse concurso ficou famoso pela segurança com que se houve nas arguições, e pelo brilho e profundeza com que dissertou sobre a filosofia de HEgEL, a ponto de merecer rasgados elogios de Pedro Lessa, um dos examinadores. Teve o Prof. João Arruda por opositores os bachareis LuIs Gonzaga Mendes de Almeida, Alonso Guayanaz da Fonseca, João Coelho Gomes Ribeiro, Francisco Eugenio de Toledo, José Mendes e Teofilo Benedicto de Souza Carvalho.

Classificado em primeiro logar, e José Mendes em segundo, foi o Prof. Joño Arruda nomeado por decreto de 17 de outubro de 1906, tomando posse a 29.

Abrio-se-lhe então à atividade mental larguissimo ramo de investigações, em que mais aperfeiçoou os seus dilatados aconhecimentos de filosofia geral e do direito, de antropologia, de historia, de direito romano, de direito criminal, de direito publico, de direito civil e comercial. Nos debates forenses mais importantes correm a ouvir-lhe os conselhos, e ninguem, com ouvil-os, deixa de alargar os horizontes doutrinarios, ou mesmo descobrir indevassados aspetos. Entre os mais notaveis livros que publicou, lembraremos os Comentários à lei do Casamento Civil, e a Lei sobre Letra de Cambio, onde encara questões praticas de acentuado relevo, e as discute com agudeza e segurança notaveis.

Ao mesmo tempo, elabora preciosas monografias sobre Administração das Sociedades Anonimas, e Assembléias de Acionistas, inserta na Revista desta Faculdade, além de numerosas e eruditas contribuições na Revista Juridica, na Revista dos Tribunaes, no Direito, no São Paulo Judiciario, na Revista do Direito e na Gazeta dos Tribunaes. 
Mereceram-lhe os problemas politicos e constitucionaes grande devotamento, e deixou a respeito obra extensa e varia, que ha de ser lida com a simpatia e o respeito, que despertam as convicções arraigadas e sinceras. Os seus estudos sobre Reforma Constitucional, União Sul Americana, Regimen Democratico, Arte de Governar, Introdução à Ciencia do Direito, estão a pedir edições, sob a desvelada revisão do nosso eminente colega prof. Braz de Sousa Arruda.

Da operosidade jornalistica do Prof. João Arruda dão testemunho inumeras produções estampadas na Aurora Bananalense; na Gazetinha, de Aluisio Azevedo; na Semana, de Valentim Magalhães; no Diario Mercantil, de LÉo e Gaspar da Silva; no Reporter, de Ribeirão Preto; no Comercio de Sã̃o Paulo, e seu sucessor o Jornal do Comercio, edição de São Paulo; no Jornal do Comercio, do Rio de Janeiro; ie no Estado de São Paulo.

As suas eruditas lições de filosofia do direito foram honradas com uma edição promovida por esta Faculdade, fato que, por si só, lhes testemunha o merito.

Ocupou interinamente o Prof. Joño Arruda, de Dezembro de 1930 a Fevereiro de 1931, a diretoria desta Faculdade, prestando corajosos serviços em momentos de grande agitação publica. Em Dezembro de 1941, recebeu o titulo de Professor Emerito.

Faleceu nesta cidade aos 18 de Setembro de 1943, deixando um vácuo impreenchivel na saudade de quantos o conheceram, estimaram e admiraram. À beira do tumulo, recordou o nosso ilustrado professor Genesio DE Moura, em nome de seus antigos alunos, a profunda e inolvidavel impressão que guardaram de suas lições. O prof. Cardoso de Melo Neto, então nosso Diretor, num breve, eloquente e sintetico discurso, externou a saudade e o pezar de todos os docentes, e o academico Rivaldo de Assis Cintra, o dos alunos. Aúreliano Leite, seu companheiro de lutas partidarias, celebrou-lhe o denodo e a coragem de atitudes, bem como o valor de seu grande exemplo para S. Paulo e para o Brasil. Pelagio Lobo, que, com tão luminoso talento, vem 
evocando as grandes figuras da historia academica, traçoulhe, dias depois, pelas colunas do Estado de S. Paulo, um perfil ao mesmo tempo elegante, caloroso e justo. Na impossibilidade de transcrever muito, tomaremos apenas um topico: - "JoÃo Arruda era um sabio sem alardes, e expunha o que sabia com destreza e sem jactancias."

Jorge Araujo da Veiga, filho dileto desta Casa, herdeiro do fino e culto espirito de Veiga Frlho, traçando a biografia do Prof. Joño Arruda, na Ordem dos Advogados de S. Paulo, exarou com justeza e com calor todo o apreço de S. Paulo ao ilustre extinto. Eis um topico mais incisivo: - "A ilustração de JoÃo Arruda era notavel, rara. Cultura geral, enciclopedica. Parecia tudo conhecer, desde as humanidades até os estudos superiores... E o direito, conhecia-o maravilhosamente, a fundo, nos varios ramos ou manifestações: a filosofica, a dogmatica, a historica. Lembro-me de certa vez em que João Arruda, visitando meu pae em nossa casa, ouvi deste após a retirada do amigo, a seguinte exclamação: "este homem assombra, pela cultura imensa que tem..."

Em conclusão, senhores, viveu alta e nobremente o varão insigne, cuja memoria hoje reverenciamos. Coube-lhe um belo e glorioso destino, o de viver largos anos em permanente contacto com a mocidade de sua patria, que ele tanto estremeceu e servio, e para quem, - até a hora extrema, dias antes de sua morte, incessantemente escreveu, conservando até o final momento o amor à ciência e o devotamento à juventude, -- supremas aspirações do seu nobre espirito.

Consiste a imortalidade em viver na memoria das gerações, e aquele que, como o prof. João Arruda, viveu e vive na recordação afetuosa dos discipulos e dos amigos, vive e viverá sempre como simbolo de trabalho e de honra, de labor intelectual e de nobre coragem de atitudes. 